\title{
Impacts of Nickel Nanoparticles on Grow Characteristics, Photosynthetic Pigment Content and Antioxidant Activity of Coriandrum sativum L.
}

\author{
ABDOL HOSSEIN MIRI ${ }^{1}$, ELHAM SADAT SHAKIB ${ }^{1}$, \\ OMOLBANIN EBRAHIMI ${ }^{1}$ and JAVAD SHARIFI-RAD ${ }^{2 *}$ \\ 1'Department of Pharmacognosy, Faculty of Pharmacy, Zabol Universityof Medical \\ Sciences, Zabol, Iran. \\ ${ }^{2}$ Phytochemistry Research Center, Shahid Beheshti University of Medical \\ Sciences, Tehran, Iran. \\ *Corresponding author E-mail: javad.sharifirad@gmail.com \\ http://dx.doi.org/10.13005/ojc/330329
}

(Received: October 29, 2016; Accepted: February 01, 2017)

\begin{abstract}
Medicinal plants consumption is used in various countries for treatment disease and food complementary. Nanotechnology is one of developing sciences in the world. The research performed in previous studies showed that properties of medicinal plants could be strongly affected by nanoparticles that have polluted the environment. In this study, we investigated effects of nickel nanoparticles on root and shoot elongation, relative water content (RWC), photosynthetic pigment, total ash, antioxidant activity of Coriandrum sativum $\mathrm{L}$. The results showed that nickel nanoparticle decreased the RWC, root and shoot elongation, the content of photosynthetic pigments, \%total ash. In addition, although the nanoparticles decreased the antioxidant activity. The results of this study have shown that, nickel nanoparticles have toxic effects on C. sativum L plant. This research could be a turning point in the field of nanotechnology research in medicinal plants. Other researchers can survey by themselves any aspects of the study with more focusing on molecular mechanisms.
\end{abstract}

Keywords: nickel nanoparticles, Coriandrum sativum, antioxidant activity, RWC.

\section{INTRODUCTION}

Nanotechnology is an attractive research field because the use of nanoparticles due to particular physico chemical characteristics are increasing in the various sciences ${ }^{1}$. Nanoparticles have much applied in agriculture, industry, pharmaceutical and medicine sciences ${ }^{2,3}$. In spite of the extensive growth of nanotechnology and nanomaterials through the last twenty years, the recent focus has been turned on to the potential toxicological effects on animals, humans and the environment through the exposure of metal nanomaterials ${ }^{4}$.

Nanotechnology is a new science founded ways to diverse industries and several fields of 
researches. Life sciences are no exception in this regard $^{5,8}$. Materials with at least one dimension between 1-100 $\mathrm{nm}$ are called nanoparticles ${ }^{9}$. The small size and large surface to volume ratio give them very unique and extraordinary properties which have caused significant progresses in different majors including food sciences, biomedical sciences, gene therapy, drug delivery, and cell targeting. Usage of nanoparticles has had remarkable effects on plant development and growth ${ }^{10,11}$. Although, there are many beneficial properties for nanoparticles on plant growth, the adverse effects should be also discussed.

Nanosized nickel oxide ( $\mathrm{nNiO}$ ) possesses many unique properties compared to its bulk counterpart and is extensively used as catalyzer, battery electrode, electrochromicl films, sensors magnetic materials and diesel-fuel additive ${ }^{12}$. The risks of inhalation exposure to $\mathrm{NiO}$ nanoparticles has been reported in mammal as determined with in vitro assays ${ }^{12}$.

Coriandrum sativum also known as cilantro, Chinese parsley or dhania is an annual herb in the Apiaceae. It is a soft, hairless plant growing to $50 \mathrm{~cm}$. The leaves are uneven in shape, broadly lobed at the base of the plant and slender. The flowers are borne in small umbels, white asymmetrical with the petals pointing away. In the Indian traditional medicine, a coriander is used in disorders of digestive, respiratory and urinary system, as it has diaphoretic, diuretic, carminative and stimulant. In Iranian traditional medicine, coriander has been indicated for a number of medical problems such as dyspeptic complaints, loss of appetite, convulsion and insomnia ${ }^{13,14}$.

In the current study, the effects of nickel nanoparticles on the growth factors of plant Corianderum sativum as well as the toxic activities of these nanoparticles have been investigated.

\section{MATERIALS AND METHODS}

\section{Nanoparticle}

The nickel nanoparticles were procured from Nanoamor Co., Iran. Average particle size of experimental nanoparticle was $20 \mathrm{~nm}$ and purity was $99.5 \%$. The shape of Ni nanoparticles was spherical. The nanoparticles were weighed and dispersed in distilled water at concentrations 20, 40 and 80 ppm. Then, they were sterilized at $120^{\circ} \mathrm{C}$ for 30 minutes. The nanoparticles were dispersed easily without precipitation by ultrasonicator and agglomerates were broken up with sufficient shaking. At the end, the nanoparticles were dispersed under suction for 20 minutes before use.

\section{Planting and harvesting}

Coriandrum sativum L. seeds were purchased from Pakan Bazr Co., Isfahan, Iran. The seeds were planted in 48 vases at green house of Zabol University of Medical Sciences. Every other day, the seeds were irrigated with $25 \mathrm{ml}$ water for 3 months. Then, they were treated with $25 \mathrm{~mL}$ of different nickel nanoparticle concentrations namely, 20, 40 and 80 ppm every other day for 22 days (Fig.1). The plantlets were then collected and placed in separate aluminum foils (Fig.1) and were stored at a $-80^{\circ} \mathrm{C}$ freezer.

\section{Measurement the length of root and the aerial part \\ Of the 6 coriander plants were randomly selected from each of the control and treated groups and their roots and stems length were measured by a ruler with an accuracy of $1 \mathrm{~mm}$.}

\section{Relative water content (RWC) measurement}

In order to examine the relative water content of the plant aerial parts and roots, their fresh weight (FW), dry weight (DW) and turgid weight (TW) were determined. Immediately after harvesting, the plants were weighed to measure the fresh weight. The plants $(0.5 \mathrm{~g})$ were soaked in $100 \mathrm{ml}$ of distilled water at $4^{\circ} \mathrm{C}$ in the dark for $24 \mathrm{~h}$ in order to obtain turgid weight. Then, they were left for $48 \mathrm{~h}$ at room temperature until they were completely dry and were weighed to determine the dry weight. The relative water content $(\mathrm{RCW})$ was determined by subtracting fresh weight from dry weight and multiplying this number by the difference between turgid weight and dry weight. RWC was calculated according to Smart method $^{15}$, using the following equation:

$$
\text { RWC }=[\text { fresh weight- dry weight/ turgid }
$$
weight - dry weight] $\times 100$

\section{Photosynthetic Pigment Measurement}

The photosynthetic pigment contents of the plants were measured according to the protocol described by Lichtenthaler and wellburn ${ }^{16}$ in both 
control and treated samples. Three hundred $\mathrm{mg}$ of plant aerial parts (blank and treated samples) were powdered using liquid nitrogen. Then the volume was brought to $25 \mathrm{ml}$ adding $80 \%$ acetone. The solution was centrifuged at 4800 rpm for 20 minutes. The absorbance of supernatant was measured to examine the contents of chlorophyll II a, b and carotenoids. For this purpose, the observance of the clear supernatant was read at 663.2, 663, 646.8, 645, and $470 \mathrm{~nm}$ (Shimadzo spectroscopy, A160 model, Japan). The following formula was used to calculate the pigment concentrations:

Chl a $(\mu \mathrm{g} / \mathrm{ml})=12.25 \times \mathrm{A} 663.2-2.79 \times \mathrm{A} 646.8$

$\mathrm{Chl} \mathrm{b}(\mu \mathrm{g} / \mathrm{ml})=21.5 \times \mathrm{A} 646.8-5.1 \times \mathrm{A} 663.2$

Chl a + Chl b $(\mu \mathrm{g} / \mathrm{ml})=7.15 \times$ A663. $2+18.71 \times$ A646.8

$\beta$-caroten $(\mu \mathrm{g} / \mathrm{ml})=(1000 \times \mathrm{A} 470-1.82 \times \mathrm{Ca}-85.02$ $\times \mathrm{Cb}) / 198$

\section{Measurement of\% Ni nanoparticles in total ash}

Two $\mathrm{g}$ of both treated and control plants were powdered and left for $4.5 \mathrm{~h}$ at $500-550{ }^{\circ} \mathrm{C}$ in the oven. Then, the obtained ashes were weighted and mixed with $15 \mathrm{ml} \mathrm{HCL} 2 \mathrm{M}$. The mixture was heated until the volume was $10 \mathrm{ml}$. After filtering, the obtained solution was mixed with water to get $50 \mathrm{ml}$. Finally, the absorbance of samples were measured with atomic absorption spectrometry.

\section{Antioxidant activity}

To determine the antioxidant activity of treated and untreated plants, DPPH method was used. For this purpose, the concentrations 100, 50,25 , and $12.5 \mu \mathrm{g} / \mathrm{ml}$ of methanol extract of the plants were prepared. Two $\mathrm{ml}$ of each sample was mixed with $1 \mathrm{ml}$ methanol DPPH $(0.2 \mu \mathrm{M})$ and were shaken. Then, all samples were incubated in the dark at room temperature for $30 \mathrm{~min}$. the absorbance was measured at $517 \mathrm{~nm}$ using a UV-vis spectrophotometer. Inhibition percentage of DPPH is calculated as followed:
$\%$ Inhibition $=\left(B_{0}-B_{1}\right) / B_{0} \times 100$

Where $\mathrm{B}_{0}$ and $\mathrm{B}_{1}$ represent absorbance of control and absorbance of the sample, respectively. In this assay, Vitamin $\mathrm{E}$ and butylated hydroxyanisole (BHA) were used as standards.

\section{Statistical analysis}

The experimental design was randomized complete block and each reported value is the average of three replicates. Microsoft Excel 2007 program was used to calculate and represent raw data. The variances were analyzed by SPSS (version 11.5) software. Variance was used to analyze the quantitative changes of different parameters (ANOVA). All results are reported as mean \pm standard deviation (SD). The results were considered significant if $P<0.05$, compared to control group.

\section{RESULTS}

\section{Nickel nanoparticles effects on root and shoot elongation}

To study the effects of nickel nanoparticle on plant length, six samples were selected randomly from control and treated groups (20,40, and 80 ppm). As shown in figure 2, nickel nanoparticles decreased the growth of the root and shoot elongation when compared to the control group. Although all concentrations caused decrease in plant length, only the differences at concentrations 40 and 80 ppm were significant compared to the control group $\left({ }^{* *} P<0.01\right)$. Comparing all samples with each other shows that the difference between concentrations 20 and 80 ppm is significant $\left({ }^{\star} P<0.05\right)$.

\section{Nickel nanoparticles effects on RWC}

Relative water content (RWC) is an index demonstrating the amount of water in the plant organs and shows the ability of a plant in maintaining water under stress conditions. Therefore, in an
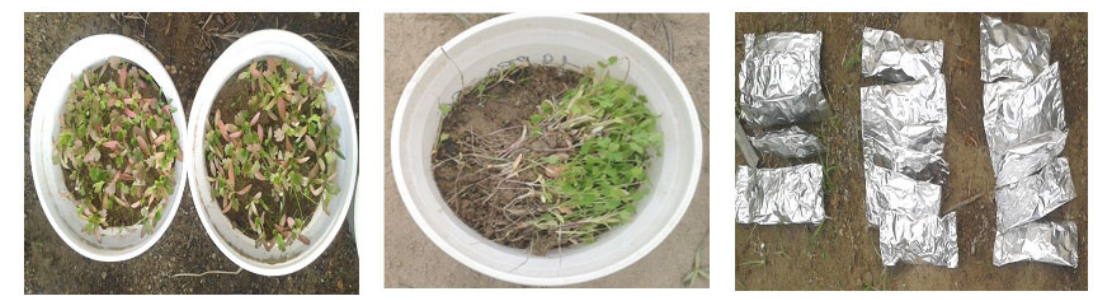

Fig. 1: Different stages of planting and harvesting of plant material. 
experimental controlled environment, the measured RWC clearly showed the response of a plant. The higher the measured amount, the greater the ability of the treatment to preserve water ${ }^{17}$. To determine the effect of nickel nanoparticles on the weight of plant parts, six plants from each control and treated groups were selected randomly and weighed.

\section{Nickel nanoparticles effects on Photosynthetic pigments}

Figure 3 shows the effects of nickel nanoparticles on photosynthetic pigment contents, including chlorophyll a, b, and carotenoids. The effect of nickel nanoparticles on photosynthetic pigment content is very different dependent on the type of pigment and nickel concentrations. Chlorophyll a was

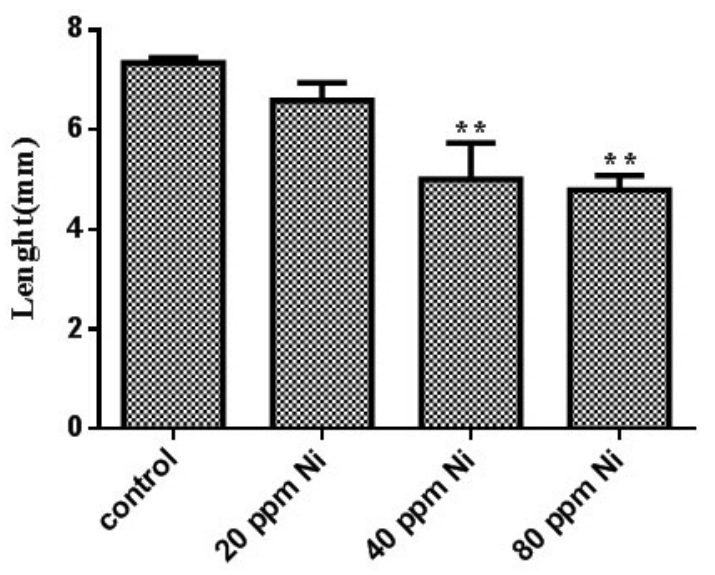

Treatment

Fig. 2: Plant height in millimeters against various concentrations of nickel nanoparticles.

Results are shown as mean \pm SD. $\left(p<0.01^{\star *}\right)$ and $(p<0.05 *)$ compared with the control group. increased at concentrations 20 and $80 \mathrm{ppm}$ while it decreased at concentration $40 \mathrm{ppm}$. In contrast, the content of chlorophyll b was decreased at concentrations 20 and $80 \mathrm{ppm}$ whereas it decreased at $40 \mathrm{ppm}$ concentration. The level of carotenoids was almost the same as control group; however it decreased at $40 \mathrm{ppm}$ and increased at $80 \mathrm{ppm}$.

\section{Nickel nanoparticles effects on total ash}

The effect of nickel nanoparticles on \% total ash of coriander plant is shown in figure 4 . The content of \%total ash was significantly different in the plants treated with nickel nanoparticles at concentrations 20 ppm $\left({ }^{\star} P<0.05\right)$, and 40 and 80 ppm $\left({ }^{\star} P<0.001\right)$.

\section{Nickel nanoparticles content in plants}

The amount of nanoparticles in each treatment of the plant was determined by atomic absorption spectrometry and the standard curve was depicted (Figure 5). According to the line equation obtained, the concentration of nanoparticles in each treatment was calculated. The results are shown in Table 2.

\section{Nickel nanoparticles effects on antioxidant activity}

To determine the antioxidant activity of coriander plants treated by various concentrations of nickel nanoparticles, the $\mathrm{IC}_{50}$ values were calculated (Table 3). Vitamin E was used as a standard natural antioxidant and $\mathrm{BHA}$ as a synthetic one. The results showed that as the concentration of nanoparticles increased; the $\mathrm{IC}_{50}$ was increased as well, showing that the antioxidant activity of the plant was decreased.

Table 1: The mean dry weight in grams coriander plant against different concentrations of nickel nanoparticles.

\begin{tabular}{|c|c|c|c|c|}
\hline & \multicolumn{4}{|l|}{ C. sativum } \\
\hline & \multicolumn{2}{|l|}{ Root } & \multicolumn{2}{|l|}{ Shoot } \\
\hline & FW (g) & DW (g) & FW (g) & DW (g) \\
\hline Control & $0.06 \pm 0.01$ & $0.02 \pm 0.01$ & $0.74 \pm 0.01$ & $0.15 \pm 0.01$ \\
\hline 20 ppm Ni & $0.2 \pm 0.1^{\star \star}$ & $0.04 \pm 0.01^{* *}$ & $0.85 \pm 0.01^{* *}$ & $0.24 \pm 0.01^{\star *}$ \\
\hline 40 ppm Ni & $0.21 \pm 0.01^{* *}$ & $0.05 \pm 0.01$ ** & $0.35 \pm 0.01^{* *}$ & $0.09 \pm 0.01^{\star *}$ \\
\hline 80 ppm Ni & $0.05 \pm 0.01$ & $0.02 \pm 0.01$ & $0.18 \pm 0.01^{\star \star}$ & $0.04 \pm 0.01^{\star *}$ \\
\hline
\end{tabular}

Results are shown as mean \pm SD. $\left(p<0.01^{* *}\right)$ compared with the control group 


\section{DISCUSSION}

The results of the present study showed that as the concentration of nickel nanoparticles increases, the growth of the plant decreases. In 2007, Lin et al. studied the phytotoxicity of nanoparticles and their inhibitory activity on germination and growth of seeds and roots (18). They examined the toxicity of $\mathrm{Al}_{2} \mathrm{O}_{3}$ nanoparticles at concentrations 20,200 , and $2000 \mathrm{mg} / \mathrm{l}$ in plants radishes, corn, lettuce, cucumbers, and canola. They found this nanoparticle phytotoxic only at the highest concentration. In addition, the phytotoxicity of $\mathrm{Zn}$ and $\mathrm{ZnO}$ was significant and decreased the root elongation of the crns tested. They found that the higher the concentration of the nanoparticle, the lesser the root elongation. The toxicity of nickel nanoparticles has been also investigated by different research groups. For instance, Gong et al. have studied the biotoxicity of nickel oxide nanoparticles ${ }^{19}$. They determined the toxicity of $\mathrm{NiO}$ nanoparticles at concentrations $10-50 \mathrm{mg} / \mathrm{L}$ on Chelorella vulgaris. They realized that this nanoparticle significantly inhibits the growth of the plant in a concentration dependent manner $(P<0.01)$. They proposed

Table 2. The concentration of nickel nanoparticles in the plants treated by 20,40 , and $80 \mathrm{ppm}$ concentrations $(n=3)$.

\begin{tabular}{lr}
\hline Treatment & Concentration \\
\hline $20 \mathrm{ppm} \mathrm{Ni}$ & 0.02 \\
$40 \mathrm{ppm} \mathrm{Ni}$ & 0.036 \\
$80 \mathrm{ppm} \mathrm{Ni}$ & 0.045 \\
\hline
\end{tabular}

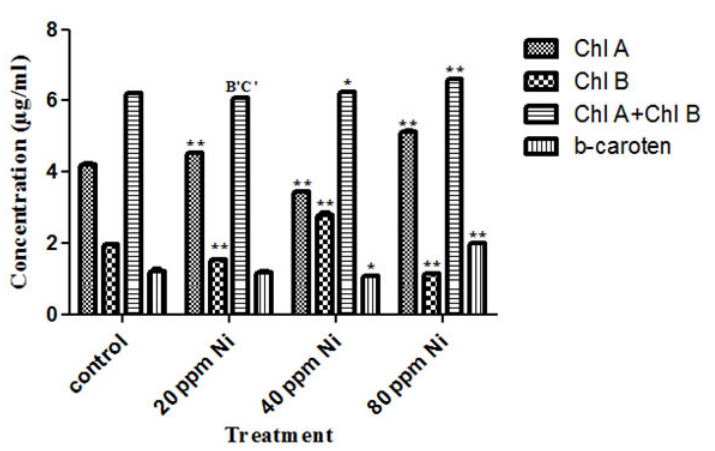

Fig. 3: Average chlorophyll a, b and carotenoids in plants at different concentrations of nickel nanoparticles. Results are shown as mean \pm SD. $\left(p<0.01^{* *}\right)$ and $(p$ $\left.<0.05^{*}\right)$ compared with the control group. nanoparticle aggregation as a possible mechanism of the nanoparticle phytotoxicity.

Taken together, it can be concluded that nanoparticles are phytotoxic at high concentrations. The absence of toxicity at lower concentrations is duo to homeostasis in plant cells. This phenomenon gives the plant the ability to grow under this situation. The future studies should focus on molecular mechanisms of nanoparticles toxicity to reveal the mechanisms of actions.

The results showed that nickel nanoparticles decreased the fresh and dry weight of aerial parts significantly $(P<0.01)$ and they did not have a significant effect on the roots. In 2012, ShengJiang et al. studied the toxicity of $\mathrm{AgNO}_{3}$ and silver nanoparticles on Spiradelha polyrhiza ${ }^{20}$. The fresh and dry weight of the plants decreased in a concentration dependent of the nanoparticles. At the highest concentration of silver nanoparticles (10 $\mathrm{mg} / \mathrm{l})$, the weights decreased $50 \%$ compared with the control group. The phytotoxicity of nanoparticles has been investigated in several other studies. For example, the effects of silver nanoparticles $(5,10$, $20,40,80$, and $160 \mu \mathrm{g} / \mathrm{L}$ ) were studied on Lemna minor $^{21}$. They also revealed the toxicity of silver nanoparticles on weights of plants. The results of our study have confirmed the results of previous studies. Nanoparticles, at high concentrations, decrease the fresh and dry weight of both roots and aerial parts. Further studies are required to uncover the precise mechanisms of action.

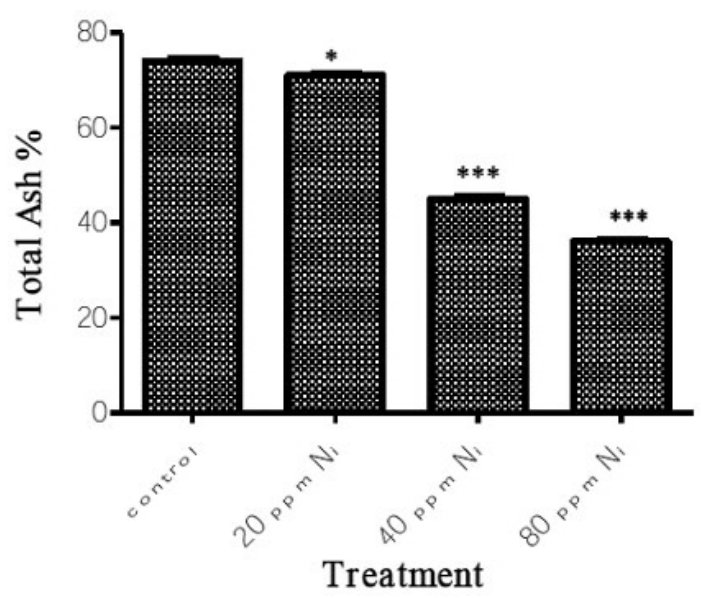

Fig. 4: \% total ash of coriander plants treated with nickel nanoparticles at 20,40 , and 80 ppm concentrations. 
Table 3. The IC50 values of coriander plants treated with and without nickel nanoparticles at concentrations 20,40 , and 80 ppm, as well as Vit E and BHA

\begin{tabular}{lrrrrrr}
\hline Concentration $(\mu \mathrm{g} / \mathrm{mL})$ & Control & $20 \mathbf{p p m ~ N i}$ & $\mathbf{4 0} \mathbf{p p m ~ N i}$ & $\mathbf{8 0} \mathbf{p p m ~ N i}$ & BHA & Vit E \\
\hline IC50 & $30 \pm 10$ & $31 \pm 10$ & $33 \pm 10$ & $34 \pm 10$ & $16 \pm 10$ & $15 \pm 10$ \\
\hline
\end{tabular}

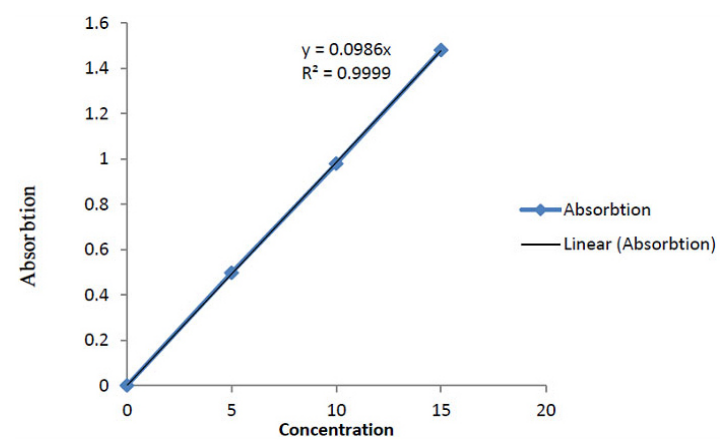

Fig. 5: The standard curve for determination of amount of nanoparticles in each treatment of the plant.

Nickel nanoparticles increased the levels of photosynthetic pigments including chlorophyll a, b, and carotenoids at high concentrations. this trend has also been observed by other research groups ${ }^{22}$. There are several proposed mechanisms for this increase in photosynthetic pigments. In general, it is suggested that different nanoparticles cause damages in the photosynthetic process. Thus, plants increase the production of these pigments to make a balance and cellular homeostasis. Type of nanoparticle, plant species, size and shape of nanoparticles are other factors influencing this phenomenon. It is recommended that in order to clarify the involved mechanisms, each of the mentioned factors to be considered separately.

The results showed a significant decrease in the amount of total ashes dependent on the nanoparticle concentrations $(P<0.001)$. According to literature survey we did, there is no similar study in this regard. However, duo to the phytotoxicity effects we observed in other morphological and biochemical factors, this weight loss in total ash can be attributed to decrease in mineral constituents of plants.

The nanoparticles levels increased in the plants as the concentration of them increased in the environment of the plants. This result suggests the environmental pollution with nanoparticles is easily transferable to the plants and as a consequence to the food chain of humans. On the other hand, this result shows that the morphological and biochemical changes observed are correlated to the increase in the nanoparticles.

The antioxidant activity of the plants decreased in a concentration dependent of nickel nanoparticles. According to our knowledge, there is no previous study for investigating the effects of nickel nanoparticles on antioxidant activities. However, the inhibition of radical scavenging activity of the plant metabolites is a possible mechanism.

In conclusion, the nickel nanoparticles showed phytotoxic effects on morphological and biochemical properties of Coriandrm sativum. However, the precise mechanisms underlying should be investigated in future studies.

\section{REFERENCES}

1. Rad MS, Rad JS, Heshmati GA, Miri A, Sen DJ. Biological synthesis of gold and silver nanoparticles by Nitraria schoberi fruits. American Journal of Advanced Drug Delivery. 2013; 1 (2):174-9.

2. Rad JS, Alfatemi MH, Rad MS, Rad MS, Sen DJ, Mohsenzadeh S. In-vivo titanium dioxide
(TiO2) nanoparticles effects on chromosomal abnormalities and lactate dehydrogenase activity. American Journal of Advanced Drug Delivery. 2013; 1(3):232-7.

3. Sharifi-Rad J, Hoseini Alfatemi S, SharifiRad M, Iriti M. Antimicrobial synergic effect of Allicin and silver nanoparticles on skin 
infection caused by methicillin resistant Staphylococcus aureus spp. Annals of medical and health sciences research. 2014; 4 (6):863-8.

4. Sharifi Rad J, Karimi J, Mohsenzadeh S, Rad MS, Moradgholi J. Evaluating SiO2 Nanoparticles Effects on Developmental Characteristic and Photosynthetic Pigment Contents of Zea mays L. Bulletin of Environment, Pharmacology and Life Sciences. 2014; 3 (6):194-201.

5. Daniel MC, Astruc D. Gold Nanoparticles: Assembly, Supramolecular Chemistry, Quantum-Size-Related Properties, and Applications Toward Biology, Catalysis, and Nanotechnology. Chem Rev. 2004; 104 (1):293-346.

6. Shi D, Sadat ME, Dunn AW, Mast DB. Photo-fluorescent and magnetic properties of iron oxide nanoparticles for biomedical applications. Nanoscale. 2015; 7 (18):820932.

7. Sharifi-Rad J, Sharifi-Rad M, Teixeira da Silva J.A. Morphological, Physiological and Biochemical Responses of Crops (Zea mays L., Phaseolus vulgaris L.), Medicinal Plants (Hyssopus officinalis L., Nigella sativa L.), and Weeds (Amaranthus retroflexus L., Taraxacum officinale F. H. Wigg) Exposed to SiO2 Nanoparticles. J Agr Sci Tech. 2016;18(4):1027-1040.

8. Walkey C, Das S, Seal S, Erlichman J, Heckman K, Ghibelli L, et al. Catalytic properties and biomedical applications of cerium oxide nanoparticles. Environ Sci Nano. 2015; 2 (1):33-53.

9. Ball P. Natural strategies for the molecular engineer. Nanotechnology. 2002; 13 (5):R15R28.

10. Siddiqui $\mathrm{MH}, \mathrm{Al}-$ Whaibi $\mathrm{MH}$, Mohammad F. Nanotechnology and plant sciences: Nanoparticles and their impact on plants: Springer International Publishing; 2015. 1-303

11. Thul ST, Sarangi BK. Implications of nanotechnology on plant productivity and its rhizospheric environment. Nanotechnology and Plant Sciences: Nanoparticles and Their Impact on Plants: Springer International Publishing; 2015. 37-53.

12. Wang C-B, Gau G-Y, Gau S-J, Tang C-W, $\mathrm{Bi} \mathrm{J}$-L. Preparation and characterization of nanosized nickel oxide. Catal Lett. 2005; 101 (3-4):241-7.

13. Mahendra P, Bisht S. Coriandrum sativum: A daily use spice with great medicinal effect. Pharmacogn J. 2011 ;3 (21):84-8.

14. Chawla S, Thaku M. Coriandrum sativum: A promising functional and medicinal food. Med Plants. 2013; 5 (2):59-65.

15. Smart RE. Rapid Estimates of Relative Water Content. Plant Physiol. 1974; 53, 258-260.

16. Lichtenthaler HK, Wellburn AR. Determinations of total carotenoids and chlorophylls $a$ and $b$ of leaf extracts in different solvents. Biochemical Society Transactions. 1983; 11 (5):591-2.

17. Abbaszadeh B, Ashourabadi ES, Lebaschi $\mathrm{MH}$, Kandy MNH, Moghadami F. The Effect of Drought Stress on Proline Contents, Soluble Sugars, Chlorophyll and Relative Water Contents of Balm. Iranian Journal Of Medicinal And Aromatic Plants. 2008; 4:50413.

18. Lin D, Xing B. Phytotoxicity of nanoparticles: inhibition of seed germination and root growth. Environ Pollut. 2007; 150 (2):243-50.

19. Gong N, Shao K, Feng W, Lin Z, Liang C, Sun Y. Biotoxicity of nickel oxide nanoparticles and bio-remediation by microalgae Chlorella vulgaris. Chemosphere. 2011; 83 (4):510-6.

20. Jiang HS, Li M, Chang FY, Li W, Yin LY. Physiological analysis of silver nanoparticles and $\mathrm{AgNO} 3$ toxicity to Spirodela polyrhiza. Environ Toxicol Chem. 2012; 31(8):1880-6.

21. Gubbins EJ, Batty LC, Lead JR. Phytotoxicity of silver nanoparticles to Lemna minor L. Environ Pollut. 2011;159 (6):1551-9.

22. Sharifi Rad J, Mohsenzadeh S, Sharifi Rad M, Moradgholi J. Evaluating $\mathrm{SiO}_{2}$ Nanoparticles Effects on Developmental Characteristic and Photosynthetic Pigment Contents of Zea mays L. Academy for Environment and Life Sciences. 2014; 3 (6):194-201. 